\title{
CORRECTION
}

Check for updates

Cite this: J. Mater. Chem. A, 2019, 7, 20435

DOI: $10.1039 / c 9 t a 90203 a$

www.rsc.org/MaterialsA

\section{Correction: Tailoring the ORR and HER electrocatalytic performances of gold nanoparticles through metal-ligand interfaces}

\author{
David Alba-Molina, ${ }^{a}$ Alain R. Puente Santiago, bc Juan J. Giner-Casares, ${ }^{\text {*a }}$ \\ Enrique Rodríguez-Castellón, ${ }^{d}$ María T. Martín-Romero, ${ }^{a}$ Luis Camacho, ${ }^{a}$ \\ Rafael Luque ${ }^{\text {be }}$ and Manuel Cano*a
}

Correction for 'Tailoring the ORR and HER electrocatalytic performances of gold nanoparticles through metal-ligand interfaces' by David Alba-Molina et al., J. Mater. Chem. A, 2019, DOI: 10.1039/c9ta05492h.

The authors regret the following minor errors in the published article. In eqn (4), a minus sign was missing from the final exponential term. The correct version of eqn (4) is as follows:

$$
B=0.62 n F C_{0} D_{0}^{2 / 3} v^{-1 / 6}=B^{*} n
$$

Moreover, the value of the constant $B^{*}$ was erroneously shown as $2.76 \times 10^{-2} \mathrm{~A} \mathrm{~cm}^{-2} \mathrm{rpm}^{-1 / 2}$ in the published article. The correct value of $B^{*}$ is $2.76 \times 10^{-5} \mathrm{~A} \mathrm{~cm}^{-2} \mathrm{rpm}^{-1 / 2}$. The authors thank Prof. Dr Corinne Lagrost, CNRS researcher at the Institut des Sciences Chimiques de Rennes UMR6226, for detecting both typographical errors.

The Royal Society of Chemistry apologises for these errors and any consequent inconvenience to authors and readers.

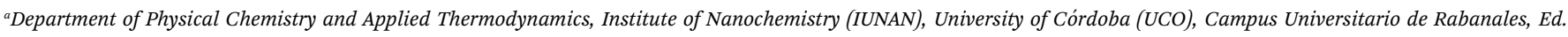
Marie Curie, Córdoba, Spain E-14014.E-mail: jjginer@uco.es; q82calum@uco.es

${ }^{b}$ Department of Organic Chemistry, IUNAN, UCO, Campus Universitario de Rabanales, Edificio Marie Curie, Córdoba, Spain E-14014. E-mail: q62alsor@uco.es

${ }^{c}$ Department of Chemistry, University of Texas at El Paso, 500 W. University Avenue, El Paso, Texas 79968, USA

${ }^{d}$ Department of Inorganic Chemistry, Crystallography and Mineralogy, Faculty of Sciences University of Málaga, Málaga, Spain

ePeoples Friendship University of Russia (RUDN University), 6 Miklukho-Maklaya str., Moscow, Russia 